\title{
Respiratory Failure Following Isolated Ziprasidone Ingestion in a Toddler
}

\author{
Chip Gresham • Anne M. Ruha
}

Published online: 6 March 2010

(C) American College of Medical Toxicology 2010

\begin{abstract}
Ziprasidone is an atypical antipsychotic approved for the treatment of schizophrenia and bipolar mania in adults and is used off label in children and adolescents. Despite increasing use of ziprasidone in both adult and pediatric populations, there remains a paucity of reports describing unintentional pediatric exposures. The following report describes a patient with isolated ziprasidone ingestion who required intubation secondary to respiratory failure. A 15-month-old previously healthy boy presented to the emergency department shortly after his father found him with approximately five partially dissolved $80-\mathrm{mg}$ ziprasidone tablets in his mouth. The child was flaccid and lethargic with no eye opening, withdrawing from pain only. Two hours after arrival, he developed worsening CNS depression with inability to protect his airway and underwent endotracheal intubation. A serum ziprasidone level was $330 \mathrm{ng} / \mathrm{mL}$ by LC/MS. The patient was extubated approximately $14 \mathrm{~h}$ later and was discharged from the
\end{abstract}

C. Gresham • A. M. Ruha

Department of Medical Toxicology,

Banner Good Samaritan Medical Center,

Phoenix, AZ, USA

A. M. Ruha

Department of Emergency Medicine,

Maricopa Medical Center,

Phoenix, AZ, USA

A. M. Ruha

Department of Emergency Medicine, University of Arizona College of Medicine,

Phoenix, AZ, USA

C. Gresham $(\bowtie)$

58 Fisher Point Drive, St. Mary's Bay,

Auckland 1010, New Zealand

e-mail: chipgresham@yahoo.com hospital shortly thereafter in good health without neurological sequelae. Isolated pediatric ingestion of ziprasidone resulting in the need for significant medical intervention has not been previously reported. We report a case of respiratory failure requiring intubation following accidental ziprasidone ingestion with confirmatory serum levels.

Keywords Ziprasidone · Ingestion · Respiratory failure · Toxicology

\section{Introduction}

Ziprasidone is an atypical antipsychotic approved for the treatment of schizophrenia and bipolar mania in adults. It is also used off label in children and adolescents to treat bipolar disorder, tic disorders, and pervasive developmental disorders $[1,2]$. The typical adult dose is $40-80 \mathrm{mg}$ twice daily while the typical child and adolescent dose is 5$40 \mathrm{mg}$ per day. After careful review of Ovid MEDLINE and BIOSIS, it appears isolated pediatric ingestions resulting in the need for significant medical intervention has not been previously reported. We report a case of respiratory failure requiring intubation following accidental ziprasidone ingestion with confirmatory serum levels.

\section{Case Report}

A 15-month-old, 11-kg, previously healthy boy presented to the emergency department shortly after his father found him with approximately five partially dissolved $80 \mathrm{mg}$ ziprasidone tablets in his mouth (five to ten times the normal adult dose). Initial vital signs included a blood pressure (BP) of $103 / 61 \mathrm{mmHg}$, heart rate (HR) of 
$116 \mathrm{bpm}$, respiratory rate (RR) of $20 \mathrm{bpm}$, an $\mathrm{SpO} 2$ of $92 \%$ while breathing room air, and a finger stick blood glucose of $121 \mathrm{mg} / \mathrm{dL}$. Physical exam revealed a patient that was flaccid and lethargic with no eye opening, withdrawing from pain only. His pupils were $3 \mathrm{~mm}$ and reactive bilaterally. His skin was warm, pink, and dry. He had bilateral breath sounds that were clear and a regular cardiac rhythm with strong bilateral brachial pulses. His abdomen was soft and non-tender with bowel sounds. He was given a $20 \mathrm{cc} / \mathrm{kg}$ bolus of normal saline intravenously and $10 \mathrm{~g}$ of activated charcoal via a nasogastric tube. Electrolytes, renal function tests, and complete blood count were normal; acetylsalicylic acid and acetaminophen levels and a urine drug screen were negative. His ECG showed a sinus rhythm of 117 with a QTc of 457 ms.

Over the next $2 \mathrm{~h}$, the child gradually developed worsening CNS depression. When the emergency physician felt the patient could no longer protect his airway, the patient was endotracheally intubated. He was then transferred to our pediatric intensive care unit by air ambulance where he arrived $3.5 \mathrm{~h}$ after intubation and $7 \mathrm{~h}$ postingestion. Just prior to transfer, the patient was placed on a midazolam drip and received one dose of a neuromuscular blocking agent in flight.

On arrival, vital signs included a HR 134 bpm, RR $28 \mathrm{bpm}$, BP $121 / 60 \mathrm{mmHg}, \mathrm{SpO} 2$ of $99 \%$ on $100 \%$ via bag-valve mask and temperature of $37.7^{\circ} \mathrm{C}$ rectally. His head was atraumatic and normocephalic with pupils that were $2 \mathrm{~mm}$ and reactive. He had a regular heart rate and rhythm with breath sounds that were clear with no wheezing. The neurological examination was initially deferred secondary to the patient having received a single dose of a neuromuscular relaxing agent via the flight crew en route. Two hours after arrival, when sedation was lightened, the patient moved all four extremities and responded to painful stimuli. The remainder of the examination was unremarkable. Laboratory results at this time were remarkable only for a $\mathrm{WBC}=28.5 \mathrm{~K} / \mathrm{mm}^{3}$. Chest X-ray revealed possible infiltrate that was consistent with aspiration pneumonia. The urine comprehensive drug screen detected only midazolam and a serum ziprasidone level, drawn $8 \mathrm{~h}$ after the ingestion, was $330 \mathrm{ng} / \mathrm{mL}$ by LC/MS. The patient was observed on the ventilator for several more hours to ensure his respiratory status was not worsening. The midazolam drip was then discontinued, and the patient was extubated. He was discharged from the hospital shortly thereafter in good health without neurological sequelae.

\section{Discussion}

Ziprasidone is an atypical antipsychotic that exhibits high binding affinity for the dopamine $\mathrm{D}_{2}$, several serotonin and alpha-1 receptors, as well as a moderate affinity for the histamine $\mathrm{H}_{1}$ receptor, while inhibiting synaptic reuptake of serotonin and norepinephrine. Its efficacy in treating bipolar mania and schizophrenia is believed to be due to the combination of antagonism at the $\mathrm{D}_{2}, 5-\mathrm{HT}_{2 \mathrm{~A}}$ and $5-\mathrm{HT}_{1 \mathrm{D}}$ receptors; agonism at the $5-\mathrm{HT}_{1 \mathrm{~A}}$ receptor; and serotonin and norepinephrine reuptake blockade. The side effect of sedation results from antagonism at the histamine $\mathrm{H}_{1}$ receptor [3, 4].

Ziprasidone has a volume of distribution of $1.5 \mathrm{~L} / \mathrm{kg}$, is greater than $99 \%$ protein bound and reaches a peak plasma concentration in 6 to $8 \mathrm{~h}$. A typical adult dose of $40 \mathrm{mg}$ twice daily would yield a steady state concentration of $118 \pm 48 \mathrm{ng} / \mathrm{mL}$. Ziprasidone is extensively metabolized with approximately one third via cytochrome P450 CYP3A4 and approximately two thirds via reduction by aldehyde oxidase [16]. There is limited single-dose pharmacokinetic data of oral ziprasidone in children. Sallee et al. compared single-dose pharmacokinetics in children and adolescents to known adult data and found oral ziprasidone exhibited linear pharmacokinetics. In one of their groups, eight patients ranging from $16-30 \mathrm{~kg}$ were given a single dose of $5 \mathrm{mg}$. Maximum serum ziprasidone concentrations were $36 \pm 14 \mathrm{ng} / \mathrm{mL}$, and the time they were attained was $5.0 \pm 2.8 \mathrm{~h}$ with the $\mathrm{t}_{1 / 2}$ being $3.3 \mathrm{~h}$ [11].

In a review of the medical literature from 1950 through 2008 using Ovid MEDLINE and 1969 through 2008 using BIOSIS, we were able to identify only nine reports, that were not poison center reviews, of pediatric exposures to ziprasidone that were either accidental ingestions or intentional overdoses [5-7]. Three separate poison center reviews, one being multi-center, included pediatric patients but provided very little information about the individual pediatric exposures $[3,10,15]$. None of the nine case reports or poison center reviews reported ziprasidone levels. Sedation was the most common clinical effect reported [3-14], but medical intervention was only required in one patient. This was a 17-year-old who also ingested buproprion, clonazepam, and lorazepam, so it is impossible to attribute his symptoms to ziprasidone only $[3,14]$.

Accidental isolated ziprasidone ingestions have been reported previously in children without deleterious effect. This is the first case report where such an ingestion produced CNS depression severe enough to result in respiratory failure requiring emergent intubation. Although the decision to intubate was made on a clinical basis without objective data demonstrating respiratory acidosis, the serum ziprasidone level of $330 \mathrm{ng} / \mathrm{mL} 8 \mathrm{~h}$ postingestion was consistent with toxicity secondary to this agent. Additionally, the patient's oxygen saturation of $92 \%$ upon presentation supports respiratory depression. While TLC with gas chromatography-mass spectrometry (GC/MS) confirmation cannot exclude all other potential co-ingestions, 
we feel confident that there were none. The patient's history did not support other ingestions, and the only other agent detected in the urine by TLC and GC/MS was midazolam, which the patient received during transfer.

Despite increasing use of ziprasidone in both adult and pediatric populations, there remains a paucity of reports describing unintentional pediatric exposures. We believe as ziprasidone becomes more common in households, emergency physicians, toxicologists, and poison centers will see an increase in accidental exposures. This case emphasizes the importance of close monitoring of pediatric ziprasidone ingestions as respiratory depression requiring intubation may occur. We believe observing a pediatric patient after ingestion of ziprasidone for 4-6 $\mathrm{h}$ in the emergency department while monitoring for signs of respiratory depression is reasonable.

\section{References}

1. Malone RP, Delaney MA, Hyman SB et al (2007) Ziprasidone in adolescents with autism: an open-label pilot study. J Child Adolesc Psychopharmacol 17(6):779-790

2. Biederman J, Mick E, Spencer T et al (2007) A prospective openlabel treatment trial of ziprasidone monotherapy in children and adolescents with bipolar disorder. Bipolar Disord 9(8):888-894

3. LoVecchio F, Watts D, Eckholdt P (2004) Three-year experience with ziprasidone exposures [letter]. Am J Emerg Med 23(4):586587
4. Reilly TH, Kirk MA (2007) Atypical antipsychotics and newer antidepressants. Emerg Med Clin North Am 25:477-497

5. Lackey G, Alsop J, Albertson T (2002) A one year review of pediatric ziprasidone ingestions [abstract]. J Toxicol Clin Toxicol 40(5):624

6. Bryant SM, Zilberstein J, Cumpston KL et al (2003) A case series of ziprasidone overdoses. Vet Hum Toxicol 45(2):81-82

7. Biswas AK, Zabrocki LA, Mayes KL et al (2003) Cardiotoxicity associated with intentional ziprasidone and buproprion overdose. J Toxicol Clin Toxicol 41(2):101-104

8. Anita SX, Sholevar EH, Baron DA (2005) Overdoses and ingestions of second-generation antipsychotics in children and adolescents. J Child Adolesc Psychopharmacol 15(6):970-985

9. Teich J (2003) Side effects of ziprasidone. Am J Psychiatry 160:1355-1356

10. Klein-Schwartz W, Lofton AL, Benson BE et al (2007) Prospective observational multi-poison center study of ziprasidone exposures. J Toxicol Clin Toxicol 45:782-786

11. Sallee FR, Miceli JJ, Tensfeldt $T$ et al (2006) Single-dose pharmacokinetics and safety of ziprasidone in children and adolescents. J Am Acad Child Adolesc Psych 45(6):720-728

12. Isbister GK, Balit CR, Kilham HA (2005) Antipsychotic poisoning in young children. A systematic review. Drug Saf 28 (11): $1029-1044$

13. DuBoise D (2005) Toxicology and overdose of atypical antipsychotic medications in children: does newer necessarily mean safer? Curr Opin Pediatr 17(2):227-233

14. Lofton AL, Klein-Schwartz W, Spiller HA et al (2004) Prospective multi-center study of ziprasidone exposures [abstract]. J Toxicol Clin Toxicol 42(5):726

15. Forrester MB (2008) Pattern of ziprasidone exposures reported to Texas poison centers, 2001-2005. Human Exp Toxicol 27(4):355361

16. Geodon [package insert] (2007). Pfizer, New York 